\title{
Cardiotonic Steroids as Modulators of Neuroinflammation
}

\section{Ana Maria Orellana ${ }^{\dagger}$, Paula Fernanda Kinoshita ${ }^{\dagger}$, Jacqueline Alves Leite ${ }^{\dagger}$, Elisa Mitiko Kawamoto and Cristoforo Scavone*}

Department of Pharmacology, Institute of Biomedical Science, University of São Paulo, São Paulo, Brazil

Cardiotonic steroids (CTS) are a class of specific ligands of the $\mathrm{Na}^{+}, \mathrm{K}^{+}-$ATPase (NKA). NKA is a P-type ATPase that is ubiquitously expressed and although well known to be responsible for the maintenance of the cell electrochemical gradient through active transport, NKA can also act as a signal transducer in the presence of CTS. Inflammation, in addition to importantly driving organism defense and survival mechanisms, can also modulate NKA activity and memory formation, as well as being relevant to many chronic illnesses, neurodegenerative diseases, and mood disorders. The aim of the current review is to highlight the recent advances as to the role of CTS and NKA in inflammatory process, with a particular focus in the central nervous system.

Keywords: cardiotonic steroids, NKA, inflammation, immunomodulation, NF-кB, ouabain

\section{INTRODUCTION}

Inflammation is an important contributor to the protection of the organism against injuries and in the maintenance of homeostasis (1), as well as being relevant in the central nervous system (CNS) to a number of key processes, including memory formation (2). However, in chronic and uncontrolled pathological conditions, such as diabetes (3), Alzheimer's disease (4), and Parkinson's disease (5), inflammatory processes can be detrimental. Inflammatory processes can modulate the activity of many different proteins, including $\mathrm{Na}^{+}, \mathrm{K}^{+}$-ATPase (NKA) (6), which is a conserved membrane protein that maintains the electrochemical gradient of the cell membrane using ATP as its energy source. Cardiotonic steroids (CTS) are natural ligands of NKA that can, in a dose-dependent manner, inhibit NKA pump activity (7) or trigger the activation of signaling pathways, such as Ras-Raf-MAPK and inositol trisphosphate receptor (InsP3R) activity, which can evoke calcium oscillations, in turn leading to the activation of the inflammation-associated transcription factor nuclear factor-kappa $\mathrm{B}(\mathrm{NF}-\kappa \mathrm{B})(8)$.

Numerous studies have shown CTS to modulate the function of many immune cells, both in vitro and in vivo, with effects via the inhibition of NF- $\mathrm{\kappa B}$ and MAPK, thereby controlling some key cellular processes, such as proliferation and differentiation, as well as cytokine production (9-14).

This article reviews the literature addressing CTS effects in immune modulation, with a particular emphasis on effects in the CNS. This is of some importance as a growing body of data indicates a significant role for central inflammatory processes in the etiology and course of many neurodegenerative diseases and mood disorders.

\section{$\mathrm{Na}^{+}, \mathrm{K}^{+}$-ATPase: A BRIEF DESCRIPTION}

For many years, NKA has aroused the interest of many groups in studying not only its pumping function, structure, and biochemistry but also, more recently, its role in signal transduction (15-17). 
NKA is well known to be responsible for the maintenance of ionic homeostasis where the hydrolysis of one molecule of ATP allows the establishment of an electrochemical gradient through the cellular efflux of three $\mathrm{Na}^{+}$ions and an influx of two $\mathrm{K}^{+}$ions. NKA is also important to the provision of cellular energy, through the cotransport of other substances, over the plasma membrane, given that many co- or counter-transporters use the $\mathrm{Na}^{+}$and $\mathrm{K}^{+}$ ionic gradients (18). A further crucial role for the NKA is the re-establishment of the ionic gradient following neuronal action potential firing. This is due to the natural $\mathrm{Na}^{+}$and $\mathrm{K}^{+}$diffusion potential across the cell membrane, which establishes a steady state that is vital for all excitable tissues, and which needs to be repolarized after neuronal depolarization $(15,18)$.

NKA consists of two protomers, each is composed of $\alpha$ - and $\beta$-subunits associated with a third protein, the $\gamma$-subunit or FXYD2 (18). Four different isoforms of the NKA $\alpha$-subunit have been identified ( $\alpha 1-4)$, three $\beta$ isoforms $(\beta 1-3)$, and seven different FXYD accessory proteins (19). Interestingly, the distribution of the different isoforms varies according to cell type, tissue, stage of development, and species (19-21). The isoforms $\alpha 1, \alpha 2, \alpha 3$, and $\alpha 4$ have different expression profiles, with the $\alpha 1$ subunit being ubiquitously expressed and uniformly distributed, $\alpha 2$ being predominant in some specific cell types, including astrocytes and cardiac myocytes, $\alpha 3$ being more highly expressed in neurons and the ovaries, while $\alpha 4$ can be found only in spermatozoa (15, $19,22,23)$. The NKA $\beta$-subunit seems to be a specific chaperone that is essential for both the traffic and correct plasma insertion site of newly synthesized $\alpha$-subunits (24). Furthermore, the $\beta$-subunit can even influence pump activity, given its modulation of $\mathrm{K}^{+}$affinity for the pump binding sites $(25,26)$. Interestingly, $\beta 1$ and $\beta 2$ isoforms can both be found in the brain, with astrocytes expressing $\alpha 1$ and $\alpha 2$ in combination with $\beta 2$, while neurons express $\alpha 1$ and $\alpha 3$ in combination with $\beta 1$ or $\beta 2(15,27)$.

\section{IMPORTANCE OF NKA SUBUNITS IN INFLAMMATION: A GENERAL APPROACH}

Over the last decade, many studies have suggested an interesting relationship between inflammatory process and the different NKA subunits, the main points of which will be summarized here.

It is well established that mitogenic activation of human peripheral blood lymphocytes by phytohemagglutinin (PHA) is accompanied by an enhancement of NKA activity, followed by an increase in $\mathrm{K}^{+}$and $\mathrm{Na}^{+}$transport $(28,29)$. This is dependent on new protein transcription $(30,31)$, and follows $\alpha 1$ and $\beta 1$ mRNA up-regulation (32). In 2002, Chiampanichayakul et al. showed for the first time that an antibody anti-NKA $\beta 3$ subunit was able to down-regulate the proliferation of both T- and B-lymphocytes, as well as the production of interleukin (IL)-2, IL-4, IL-10, and interferon-gamma (IFN- $\gamma$ ), in vitro (33).

In a model of systemic inflammation, male Sprague-Dawley rats that received an injection of Complete Freund's adjuvant, which includes inactivated Mycobacterium tuberculosis, presented both $\alpha 1$ - and $\alpha 3$-NKA isoform up-regulations, especially in primary afferent neurons, after 23 and $24 \mathrm{~h}$ (34). Furthermore, a recent study has brought some new insight as to how NKA may be involved in inflammatory processes in the somatosensory system (35). This study suggested that the FXYD2 subunit interaction with $\alpha 1$-subunit in murine nociceptive neurons negatively regulated pump activity, leading to membrane potential depolarization of these neurons, which can facilitate excitatory afferent neurotransmission, thereby facilitating allodynia. When the group used FXYD2-deficient mice, allodynia was more quickly abolished (35).

In general, it seems that the differences in the NKA isoform functions and distribution contribute somehow to the complexity of the inflammatory responses.

In 4-month-old rat hippocampus, the systemic injection of lipopolysaccharide (LPS) decreased both total NKA activity, and $\alpha 2$ and $\alpha 3$ isoforms, although in adult rats there was no significant difference (36). In accordance with these findings, in vitro experiments showed that inflammation induced by LPS-treated primary astrocytes co-cultured with newborn cortex endothelial cells also involves NKA downregulation (37). An LPS-dependent decrease in total NKA activity in young rats can be rescued by intermittent fasting (IF), as well as in older rats to a lesser degree (36), suggesting an age-associated susceptibility of NKA activity modulation by inflammatory process.

However, in the rat cerebellum, there is an age-related decline of NKA activity, arising from a decrease in the cyclic GMP-PKG pathway in cerebellum. There is also an effect of glutamatergic activity in the modulation of alpha 2,3-NKA due to impairments in PKG signaling. A failure in the correction of ionic disturbances mechanism present in aging processes could also increase the probability of occurrence of degenerative disorders (38). As such, NKA activity can be modulated by different stimuli, with consequences for the neuro-inflammatory processes that are present in all neurodegenerative diseases (39) (Figure 1).

\section{NKA AND NEUROINFLAMMATION}

In the CNS, inflammatory processes utilize a wide array of immunological cells, including the resident immunological cells, microglia, and astrocytes (40). However, in a pathological situation, monocyte-derived macrophages, present in the perivascular space, are able to cross the blood-brain barrier (BBB), with lymphocytes also being able to transverse the epithelial bloodcerebrospinal fluid barrier (BCSFB) surrounding the choroid plexus (41-43).

When exposed to cytokines, innate immune modulators, hypoxia, or other damaging stimuli, astrocytes are able to release cytokines and other immune signaling molecules (40, 44), followed by changes in $\mathrm{Ca}^{2+}$ signaling system and $\mathrm{Na}^{+}$transports during inflammation (37). Little can be stated generally about the microglial response, due to inflammation heterogeneity and complexity in different pathological contexts (45).

It is important to note that NKA plays a significant role in central inflammation, which is apparent in diabetic rats, where inflammation-associated increases in tumor necrosis factor (TNF)- $\alpha$ and IL-1 $\beta$, as well as decreased NKA activity, result in memory impairment (46). Similarly, decreased NKA activity is evident in a model of traumatic brain injury (TBI) (47), which is 


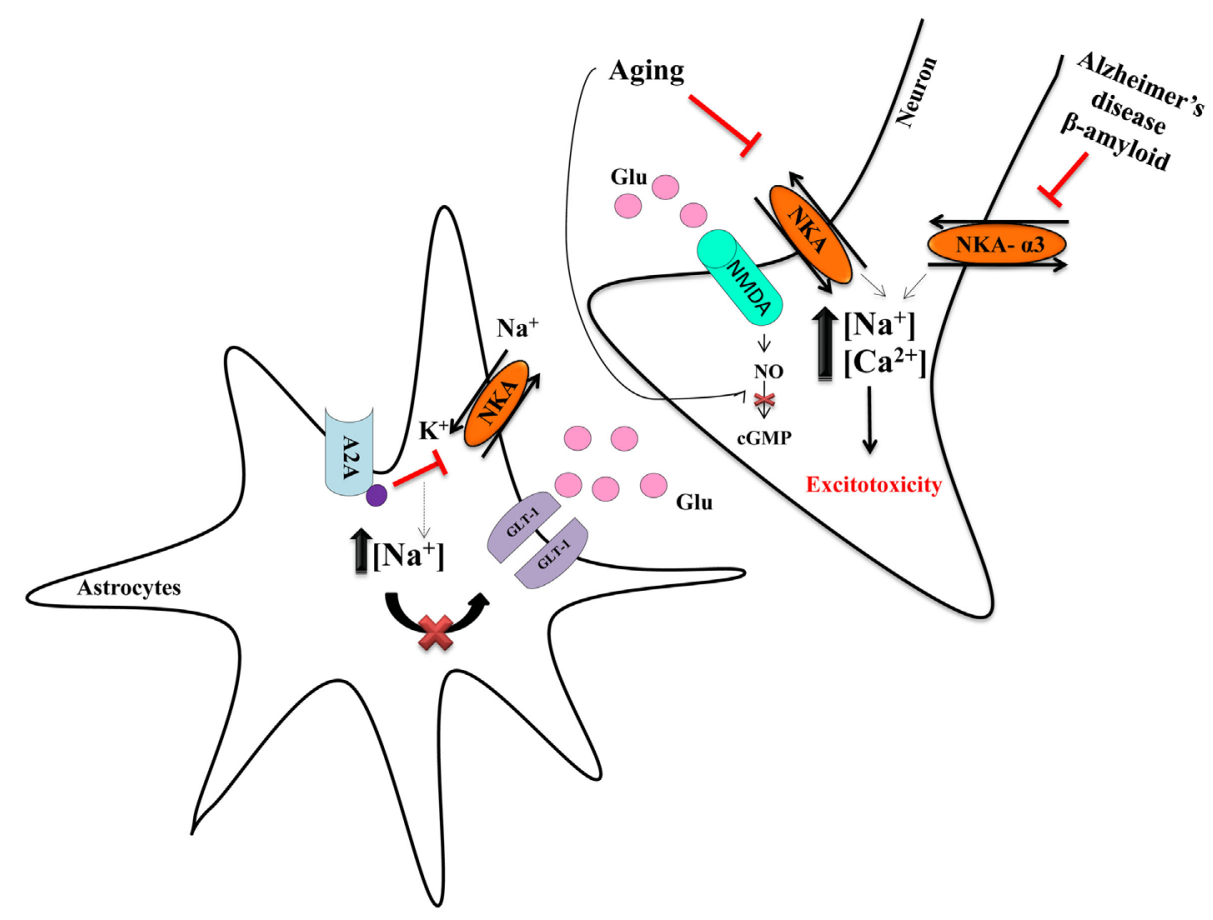

FIGURE 1 | Neurodegeneration and NKA. Astrocytes are important to regulate the release of glutamate and its provision to neurons. NKA has an important role in the control of the glutamate transporter-1 (GLT-1) in astrocytes, because the concentration of Na+ modulates the uptake of glutamate (55). The adenosine A2A receptor decreases NKA activity, leading to increased intracellular $\mathrm{Na}^{+}$concentration, which impairs glutamate uptake, resulting in more glutamate availability in the synaptic cleft (55). Such excess of glutamate overactivates the NMDA receptor, leading to increase intracellular $\mathrm{Na}^{+}$and $\mathrm{Ca}^{2+}$, in turn driving excitotoxicity (55). The decrease of NKA is mostly deleterious and amylospheroids, which are composed of $\beta$-amyloid oligomers and $\alpha$-synuclein, interact with $\alpha 3-N K A$, thereby impairing its activity. Such data indicate NKA to have an important role in neurodegeneration and neurodegenerative diseases (52, 53). Our group showed that aging is also an important factor that decreases NKA activity $(36,38)$.

prevented by exercise pre-conditioning, indicating that modulating NKA can determine the brain's subsequent response to damage (6).

Differences between brain region responses during systemic inflammation have been found in an animal model of sepsis, with NKA inhibition being faster in the cortex versus the hippocampus (48). This effect is not due to differences in NKA mRNA levels or in NKA isoforms, but could be due to a post-translational modification or to an altered oxidative stress response. Only in the cortex does an increase in NKA activity follow antioxidant administration, suggesting that variations in oxidative status may play a more important role in the regulation of cortical NKA and thereby have a differential effect on the cortex inflammatory response versus that in the hippocampus (48). The hippocampus seems more vulnerable to inflammation and, at least partly via differential NKA antioxidant effects, is more vulnerable in neurodegenerative diseases, including Alzheimer's disease (49).

In postmortem brains of Alzheimer's disease patients, NKA activity is diminished compared to that of age-matched normal brains (50). Such results were reproduced in an in vitro model of hippocampal neurons treated with $\beta$-amyloid (51), as well as in an in vitro model of frontal cortex neurons, where the addition of antioxidants, such as genistein, afforded a protective effect by increasing NKA activity (50). The mechanism underlying such decreased NKA activity was recently proposed. The amylospheroids, amyloid $\beta$-protein $(A \beta)$ oligomers typically found in postmortem brains of Alzheimer's disease patients, can interact with $\alpha 3$-NKA impairing its activity, in turn leading to the activation of voltage-dependent calcium channels, mitochondrial abnormalities, and neurodegeneration (52) (Figure 1).

In addition, an increased sodium concentration in frontal and parietal cortex, as well as an increased potassium concentration in the cerebellar tissue of Alzheimer's disease patients has also been shown. The same pattern appears in the cerebrospinal fluid (CSF) and was also replicated in vitro when astrocytes were treated with $\beta$-amyloid protein. In fact, Alzheimer's disease is also related to impaired glutamate clearance, which contributes to an ionic imbalance (53).

During inflammation, an increase in $\mathrm{N}$-methyl D-aspartate (NMDA) receptor phosphorylation is observed, with increased IL-1 $\beta$ release from astrocytes also evident (54). When a co-culture model of astrocytes pre-activated by an inflammatory stimulus was treated with Ifenprodil, Lundborg and colleagues observed that this drug could be a potent anti-inflammatory in astrocytes, following its restoration of $\mathrm{Ca}^{2+}$ levels and increased NKA expression (54).

In astrocytes, there is a crosstalk between $\alpha 2-\mathrm{NKA}$ isoform and GLT-I, an astrocytic glutamate transporter, that seems to be regulated by the $\mathrm{Na}^{+}$pump (55) (Figure 1). Furthermore, adenosine $\mathrm{A} 2 \mathrm{~A}$ receptors (A2AR), present in astrocytes, have an important role in plasticity and neurodegeneration (55). The activation of these receptors decreases NKA activity, which, as a 
result, inhibits glutamate uptake. In a model of A2AR knockout animals, increased astrocytic glutamate uptake occurred, coupled to increased expression of $\alpha 2$-NKA in the cortex and striatum. This suggests a role for NKA in neurodegeneration (55), including Parkinson's disease, given that in 2004, it was discovered that $\alpha 3$-NKA mutations are involved in rapid-onset dystonia parkinsonism that reveals that NKA could have an important role in Parkinson's disease (56). Of note, extracellular $\alpha$-synuclein can interact with $\alpha 3$-NKA to form clusters in the membrane of neurons that reduce the extrusion of $\mathrm{Na}^{+}$and which may be a relevant neuropathological change in Parkinson's disease (57). In addition, there is also evidence that $\alpha 1-\mathrm{NKA}$ overexpression drives axon initial segment abnormalities and that by reducing its expression, these and other phenotypes could be corrected in an Angelman syndrome murine model (58). The lack of NKA is involved in neurodegeneration given that $\alpha$-NKA deletion in Drosophila photoreceptors lead to the loss of visual function, as well as an increase in neurodegeneration (59).

\section{CARDIOTONIC STEROIDS, THE SPECIFIC LIGANDS OF NKA}

Cardiotonic steroids are a class of compounds that have been used to treat congestive heart failure since the eighteenth century (60). These compounds bind specifically to NKA, inhibiting its activity in a dose-dependent manner. Furthermore, they can also activate wider cellular signaling pathways, mediating changes in intracellular $\mathrm{Ca}^{2+}$ homeostasis, control of cellular growth, and gene expression (19, 61-64).

Cardiotonic steroids can be divided into cardenolides and bufadienolides, according to their origins (7) and molecular structure $(19,65,66)$, being subsequently classified as endogenous hormones in the 1990s. Two cardenolides, digoxin (67) and ouabain (68), and several bufadienolides (69-71) have been identified in human tissues. They are proposed to be produced in the hypothalamus and adrenal gland $(19,64,72)$, although there is some controversy regarding this, as some work has failed to show their presence in human plasma (73).

Numerous studies have shown CTS, as natural ligands of NKA, to have modulatory effects on immune cells functioning in vitro and in vivo $(9-11,13,14)$.

\section{ANTI-INFLAMMATORY PROPERTIES OF CTS}

In 1997, Matsumori et al. demonstrated that ouabain reduced the production of the pro-inflammatory cytokines, IL- 6 and TNF- $\alpha$, in LPS-stimulated human peripheral blood mononuclear cells, as similarly observed in vivo, in LPS-treated mice (12). Following this work, other studies have demonstrated anti-inflammatory and analgesic effects of CTS in mice. In the classical paw edema model, pretreatment with ouabain reduced carrageenan-, zymosan-, 48/80-, and PGE2-induced edema and vascular permeability $(14,74)$, with bufalin leading to a reduction in carrageenan-induced paw edema, due to the inhibition of NF- $\kappa \mathrm{B}$ activation and reduced pro-inflammatory protein expression, including inducible nitric oxide synthase (iNOS), cyclooxygenase-2, TNF- $\alpha$, IL- $1 \beta$, and IL-6 (13). Furthermore, bufalin has an antinociceptive effect, due, at least in part, to its reduction of TNF- $\alpha$ and IL- $1 \beta$ release (13). Moreover, bufalin inhibits inflammation and migration of TNF- $\alpha$-induced fibroblast-like synoviocytes, as well as reducing IL-1 $\beta$, IL- 6 , IL-8 expression and decreasing the secretion of matrix metalloproteinase-9 (MMP-9), driven by its suppression of NF- $\mathrm{\kappa B}$ activation. These results suggest a potential modulatory effect of bufalin in diseases, such as rheumatoid arthritis (75).

Similar to bufalin, ouabain has the ability to reduce proinflammatory cytokine production, such as IL- $1 \beta$ and TNF- $\alpha$, likewise inhibiting NF- $\kappa \mathrm{B}$ and p38 MAPK signaling pathways (11, 14) as demonstrated in a study showing that ouabain decreases intraperitoneal polymorphonuclear cell concentrations induced by several stimuli, as well as inhibiting leukocyte migration in vitro $(14,74,76)$. A similar anti-inflammatory effect was also seen with oleandrin and digitoxin $(77,78)$.

Recently, a subset of IL-17-producing cells has been linked to chronic inflammatory processes (79). These cells are described as a new population of effector T cells, known as Th17 cells (80), and are characterized by retinoic acid orphan receptor (ROR)- $\gamma \mathrm{t}$ transcription factor and by IL-17A and IL-17F production (81), but not T-bet or GATA-3 transcription factors (82). Several studies have investigated digoxin effects in Th17 cells (83-85). Treatment with digoxin, in a mouse and human $\mathrm{CD} 4^{+} \mathrm{T}$ cell culture, inhibited naïve CD4 polarization to Th17 cells and reduced IL-17A protein expression. These effects were due to the inhibition of ROR $\gamma t$ transcriptional activity. Furthermore, in experimental autoimmune encephalomyelitis, a multiple sclerosis model and Th17-mediated disease, treatment with digoxin, delays disease onset and reduces disease severity. IL-17 levels produced by infiltrating cells were also decreased (83).

Taken together, numerous studies have shown CTS to modulate the function of immune cells in vitro and in vivo. These antiinflammatory effects are mainly mediated through NF- $\mathrm{\kappa B}$ and MAPK inhibition. Besides CTS effects in the periphery as indicated above, some studies have also been carried out in the CNS, although the exact mechanisms or signaling pathways involved are still poorly understood. In the next section, studies are described that evaluate the functions of CTS in neuroinflammation.

\section{CTS AND IMMUNE RESPONSE IN THE CNS}

Neuroinflammation is currently a hot topic, primarily due to its association with neurodegenerative diseases, such as Parkinson's disease and Alzheimer's disease, as well as its association with mood disorders and cancers. As such, neuroinflammation has become a highly significant therapeutic target (86).

Cardiotonic steroids can have contrasting effects on neuroinflammation, as determined by variations in concentration, the route of administration, cell type, specific brain region, and time course. Ouabain is one of the most studied CTS in the CNS. 
Although ouabain-like compounds are supposed to be produced in the hypothalamus (47), there has been little investigation as to its central effects, including the regulation of central inflammatory responses and whether the CTS are able to cross the $\mathrm{BBB}$ by getting CNS entry via the fenestrated vasculature adjacent to the circumventricular organs (87).

Many groups have reported that low concentrations of this glycoside did not inhibit NKA, instead it could activate signaling pathways that usually result in a protective response, by increasing anti-apoptotic protein expression and cell proliferation (88-90). When the cells are treated with higher concentrations of ouabain (micrometer-millimeter), NKA is inhibited and, as a consequence, $\mathrm{Na}^{+}$and $\mathrm{K}^{+}$gradients are lost leading to an influx of $\mathrm{Ca}^{2+}$ into the cell, which can drive neuronal excitotoxicity (91).

In a rat cerebellum cell culture treated with ouabain at $10 \mu \mathrm{M}$, an increase in NF- $\kappa \mathrm{B}$ nuclear translocation was observed, thereby increasing the mRNA levels of $T n f-\alpha, I l-1 \beta$, and $B d n f$. In addition, the same study showed that ouabain-induced NF- $\kappa B$ activation was dependent on the NMDA-Src-Ras signaling trigged by the MAPK pathways (91). Similar results were observed in another study from the same group, in a model of intra-hippocampal injections of $10 \mathrm{nM}$ ouabain concentrations in adult rats. At nanomolar concentration, no inhibition of the NKA activity was observed, and there was NF- $\kappa \mathrm{B}$ activation followed by an increase of Tnf- $\alpha$ and iNos mRNA levels (92). These two studies show that ouabain could increase pro-inflammatory cytokines without NKA inhibition and that NF- $\kappa \mathrm{B}, \mathrm{Src}$, and NMDA are involved in this signaling pathway. As such, ouabain could also play an important role in the control of NF- $\mathrm{\kappa B}$ activation, which can lead to adaptive responses and this could have an important impact on hippocampal memory processes, including memory formation and/or consolidation (93).

In addition, a third study from the group showed that ouabain can also play a protective role against LPS, a LPS that causes systemic immune responses and can also disrupt the BBB at higher concentrations. In these experiments, rats were pretreated with a very low concentration $(1.8 \mu \mathrm{g} / \mathrm{kg})$ of ouabain intraperitoneally before LPS. Results suggested that ouabain could decrease the nuclear translocation of $\mathrm{p} 65$, a NF- $\mathrm{BB}$ subunit, important in inflammatory responses, in the presence of LPS and also reversed LPS-induced decrease in cytoplasmic IкB levels. As a result, $I l-1 \beta$ and $i$ Nos gene expression were decreased in ouabain pretreatment, in comparison to the LPS-only group (90) (Figure 2).

As previously described, ouabain can also increase TNF- $\alpha$ release, but when animals were treated with ouabain and then challenged with LPS, there was a decrease in the levels of this cytokine. This anti-inflammatory property of ouabain was also seen in the dentate gyrus, a region of the hippocampus, with ouabain decreasing astrocyte activity in comparison to the LPS-only group (90). Such data indicate that ouabain can also be

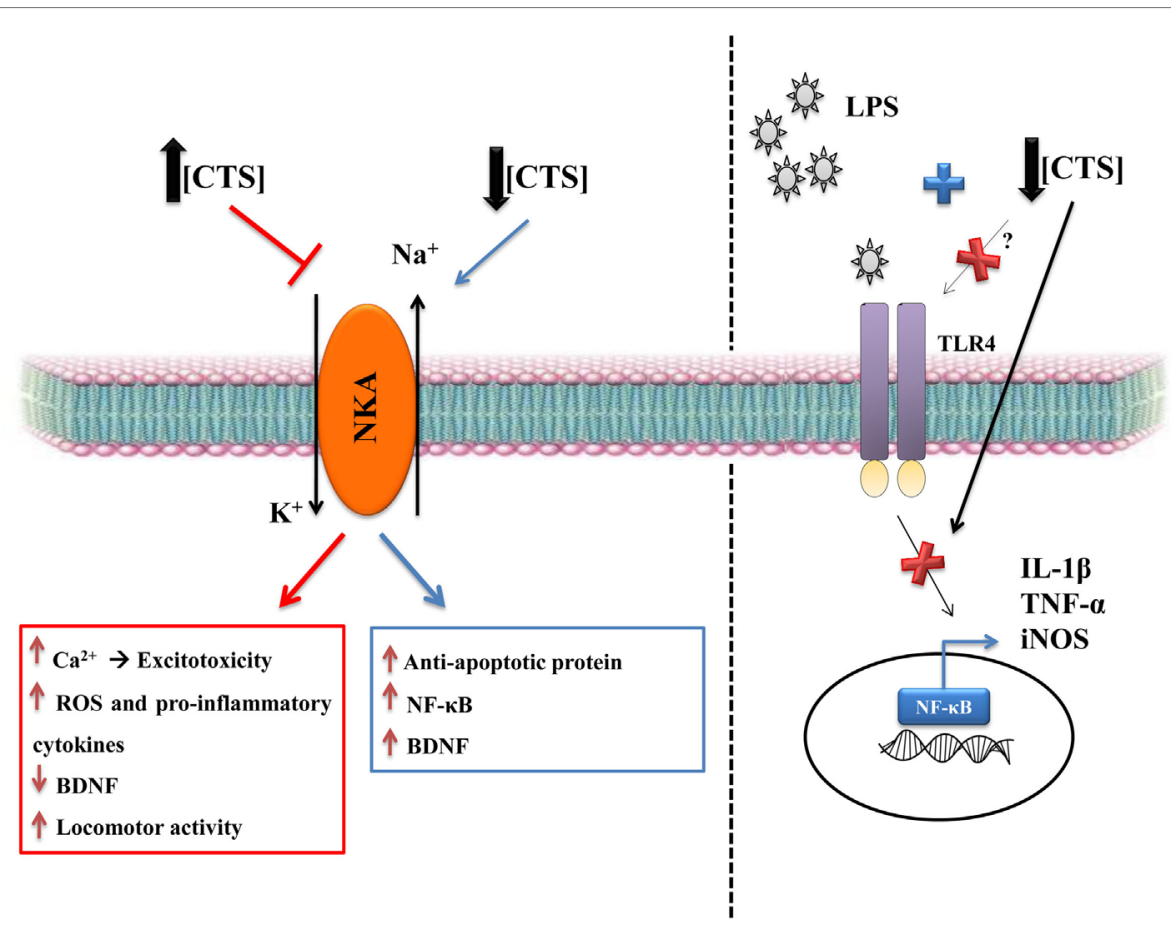

FIGURE 2 | The dual role of CTS. CTS at high concentrations are deleterious, due to NKA inhibition that consequently increases intracellular Na ${ }^{+}$, which leads to raised intracellular $\mathrm{Ca}^{2+}$ that can be the first signal of neuronal excitotoxicity (91). There is also an increase in reactive oxygen species and in pro-inflammatory cytokines and a decrease in BDNF, which is a relevant growth factor in the brain (108, 109, 114). CTS also increase locomotor activity (114), particularly when the CTS are intracerebroventricular injected, as in the ouabain model of mania (110). CTS seem to be involved in mood disorders, such as depression and bipolar disorder. Low concentrations of CTS can have a protective role, including the CNS. CTS can activate anti-apoptotic protein, such as Bcl-xL, as well as increasing NF-kB and BDNF (88-90, 100). Our group showed that the pretreatment with ouabain can be protective against neuroinflammation caused by LPS (90). This protection is due to decreased IL-1 $\beta$, TNF- $\alpha$, and iNOS mRNA levels and in the rescue of BDNF levels, thereby reverting the changes induced by LPS and, consequently, decreasing astrocytic activity, as measured by dentate gyrus GFAP (90). 
protective, during disturbances to CNS homeostasis, suggesting that ouabain alone in physiological concentrations may modulate cellular homeostasis, via pro-inflammatory cytokine regulation. It also suggests that the signaling pathway activated by ouabain could be an interesting target in neuroinflammation-associated disorders.

Interestingly, two separate studies noted that different cell types have specific ouabain responses. In rat cortex astrocyte culture, ouabain could prevent the downregulation of NKA and also could attenuate the raised levels of IL-1 $\beta$ release induced by LPS (94). However, in microglia, ouabain in low and high concentrations did not have any effect against LPS-induced cytokine release, although low concentration of ouabain evoked an increase in TNF- $\alpha$ release, which highlights that ouabain can have differential immune-modulatory effects in different cell types (95).

Furthermore, Kaur et al. have also observed that digoxin seems to have a neuroprotective effect in an ischemia/reperfusion model (96). Although, the authors did not test any inflammation parameter, the immune system is activated in this protocol with digoxin pretreatment decreasing the cerebral infarct size, resulting in better motor behavior and memory. These authors used $\mathrm{Ca}^{2+}$ channel blockers, which abolished this protection, suggesting efficacy via the $\mathrm{Ca}^{2+}$ signaling cascades (96). Another way that digoxin can be protective is by increasing levels of endogenous brain hydrogen sulfide $\left(\mathrm{H}_{2} \mathrm{~S}\right)$ (97). $\mathrm{H}_{2} \mathrm{~S}$ is severely decreased in the brain of Alzheimer's disease patients (98), suggesting that this could be another mechanism by which CTS could alleviate symptomatology in patients with neurodegenerative diseases, although the concentration may have to be very low.

Although the discussion of CTS effects on glutamatergic excitotoxicity is beyond the scope of this review, some data are worth highlighting. Ouabain, at $1 \mathrm{nM}$, seems also to be protective against kainate-induced neurotoxicity by preventing $\mathrm{Ca}^{2+}$ overload in the rat cortical neurons, indicating that the modulation of NKA can play a key role against neuronal degeneration (88). The same effect seems to occur in an experimental model of ischemia in hippocampal slice cultures, where ouabain at $120 \mathrm{nM}$ increases NKA activity. NKA inhibition is important to this ouabain-mediated protective effect, which suggest that low dose of ouabain and digoxin may be a plausible and novel treatment strategy in the management of stroke (39).

Another study showed the protective effect of oleandrin in an ischemia model in vitro and in vivo, suggesting that the protective effect of CTS in low doses is common to all types of CTS (99). It seems that oleandrin increased plasma brain-derived neurotrophic factor (BDNF) levels, this being another possible mechanism of protection against oxygen-glucose deprivation (100).

Neriifolin, another CTS, was used as a model of Parkinson's disease, because it decreases dopaminergic neuron survival through NKA inhibition, which increases the concentration of intracellular $\mathrm{Na}^{+}$, reactive oxygen species (ROS), and p53 activation (101). Similarly, marinobufagenin (MGB) can also induce endothelial oxidative stress, which may be the first step in the emergence of a stroke, as well as being of relevance in dementias, including Alzheimer's disease (102).

\section{THE INFLAMMATORY BACKGROUND IN MOOD DISORDERS AND CTS}

Accumulating evidence has shown that there is a strong correlation between mood disorders and elevated levels of CSF cytokines, such as TNF- $\alpha$ and IL-1 $\beta$, as well as increased PGE2 levels (103). Thus, it has been suggested that NKA activity and its modulation may also have a pertinent role in the etiology of mental disorders, especially bipolar disorder, which is associated with NKA activity abnormalities in erythrocytes (104) and high peripheral levels of pro-inflammatory cytokines (105).

In samples of bipolar disorders patients, ouabain binding to cortex synaptosomal preparations is lower when compared to depressed and schizophrenic groups and, at the same time, the levels of ouabain were higher in the parietal cortex from these patients in comparison with the other groups studied (106). However, this difference was not a consequence of changes in the expression of the $\alpha$-NKA isoforms. In the same study, LPS was used as a rodent model for depression, leading to an increase in the level of ouabain-like compounds in the adrenal gland (106).

However, when animals were treated with anti-ouabain antibody or a low dose of ouabain, the depressive behaviors caused by LPS was reverted. Although intriguing, the results are complex, given that some similar effects were found from the antibody and ouabain treatments. First, endogenous ouabain-like compounds respond differently from exogenous ouabain; second, different CTS can have different physiological outcomes (107) or the use of the antibody could have a positive feedback on levels of endogenous ouabain-like compounds produced in the brain, leading to a similar effect to that of exogenous ouabain (106).

Ouabain, at a high concentration $(1 \mathrm{mM})$, is also used as a model of mania, due to NKA inhibition, with this inhibition correlating with the increased cytokine levels, which are also evident in bipolar patients (108), as well with the decreased BDNF levels in hippocampus and amygdala in this rat model (109). Another important feature of ouabain in this model of mania is locomotor hyperactivity, reduced by acute or chronic treatment with memantine, lithium (110), or valproate (109). Memantine is a well-known NMDA receptor blocker (111), first indicated for the treatment of moderate-to-severe Alzheimer's disease, but that has been used off-label to treat various psychiatric disorders, including as a mood stabilizer (112). Although the mechanisms by which lithium antagonizes ouabain are not clear, it was observed in rat hippocampal slices that ouabain $(3.3 \mathrm{mM})$ treatment induces cycling electrically evoked epileptiform responses, which is delayed by pretreatment with lithium (113).

Another aspect of hyperlocomotion, including the rat ouabain model of mania, is increased levels of ROS and protein carbonyl levels, as well as the inhibition of catalase and glutathione peroxidase (114). The involvement of oxidative stress in mania was also shown following the intracerebroventricular (ICV) injection of ouabain (1-10 mM), which increased thiobarbituric acid-reactive substances (TBARS) levels and superoxide in the rat amygdala, cortex, and striatum (115).

In addition, at high concentration, ouabain ICV injection $(10 \mathrm{mM})$ modulates NKA by increasing the expression of $\alpha 2$ NKA in glial cells of the basal ganglia and $\alpha 3$-NKA in neuron of 
the frontal cortex, which may be related to hyperactivity behavior. When compared to human postmortem studies, a decrease of $\alpha 2$ NKA expression in temporal cortex of bipolar disorder patients was observed, suggesting that the specific NKA isoform expression levels may be important to the pathophysiology of mania (116).

Another interesting finding is that endogenous production of CTS in bipolar disorder patients also seems to be impaired. Bipolar disorder patients have less digoxin-like immunoreactive factor in comparison to controls, with this low level not being season dependent, as in the case of controls, where winter levels are lower than during the rest of the year (117). The ouabain-like immunoreactive factor (OLF) is also lower in bipolar disorder patients. During physical exercise, OLF is increased in nonpsychiatric patients, but in bipolar disorder patients OLF levels tend to be lower, even during exercise. As such, the regulation of OLF seems impaired in bipolar disorder patients (118).

A meta-analysis of 30 studies with a total of 2,599 participants showed evidence for a significant increase in pro-inflammatory and regulatory cytokines in bipolar disorder patients (119). However, despite ICV injection of ouabain $10 \mathrm{mM}$ in rats mimicking some aspects of bipolar disorder, ouabain injection does not increase the inflammatory molecules that are present in bipolar disorder patients, with ICV injection of high-dose OUA decreasing striatal IL-6 levels (108).

\section{CONCLUSION AND FUTURE PERSPECTIVE}

It is clear that NKA is modulated by and modulates inflammatory process through its different inflammatory molecules,

\section{REFERENCES}

1. Chovatiya R, Medzhitov R. Stress, inflammation, and defense of homeostasis. Mol Cell (2014) 54(2):281-8. doi:10.1016/j.molcel.2014.03.030

2. Sierra ABS, Diaz-Aparicio I, Encinas JM, Comeau S, Tremblay MÈ. Surveillance, phagocytosis, and inflammation: how never-resting microglia influence adult hippocampal neurogenesis. Neural Plast (2014) 2014:610343.

3. Wellen KE, Hotamisligil GS. Inflammation, stress, and diabetes. J Clin Invest (2005) 115(5):1111-9. doi:10.1172/JCI25102

4. Wyss-Coray T, Rogers J. Inflammation in Alzheimer disease - a brief review of the basic science and clinical literature. Cold Spring Harb Perspect Med (2012) 2(1):a006346. doi:10.1101/cshperspect.a006346

5. Hirsch EC, Vyas S, Hunot S. Neuroinflammation in Parkinson's disease. Parkinsonism Relat Disord (2012) 18(Suppl 1):S210-2. doi:10.1016/ S1353-8020(11)70065-7

6. Mota BC, Pereira L, Souza MA, Silva LF, Magni DV, Ferreira AP, et al. Exercise pre-conditioning reduces brain inflammation and protects against toxicity induced by traumatic brain injury: behavioral and neurochemical approach. Neurotox Res (2012) 21(2):175-84. doi:10.1007/s12640-011-9257-8

7. Bagrov AY, Shapiro JI, Fedorova OV. Endogenous cardiotonic steroids: physiology, pharmacology, and novel therapeutic targets. Pharmacol Rev (2009) 61(1):9-38. doi:10.1124/pr.108.000711

8. Xie Z, Askari A. $\mathrm{Na}(+) / \mathrm{K}(+)$-ATPase as a signal transducer. Eur J Biochem (2002) 269(10):2434-9. doi:10.1046/j.1432-1033.2002.02910.x

9. Quastel MR, Kaplan JG. Inhibition by ouabain of human lymphocyte transformation induced by phytohaemagglutinin in vitro. Nature (1968) 219(5150):198-200. doi:10.1038/219198a0

10. Pires V, Harab RC, Olej B, Rumjanek VM. Ouabain effects on activated lymphocytes: augmentation of CD25 expression on TPA-stimulated cells and with this occurring in many different ways according to cell type, tissue, age, and the dose of its specific CTS ligands, suggesting a complex role for CTS in inflammatory processes. In the CNS, inflammation has been suggested as an important mediator in major neurodegenerative diseases. As such, the role of CTS and NKA in inflammatory process provides a significant challenge for future research, including as to the role of endogenous CTS and in the modulation of NKA levels and activity, which is fundamental for the optimal functioning of the synaptic activity of the nervous system. By virtue of its involvement in such fundamental processes, the investigation of CTS is likely to drive the development of novel therapeutic interventions.

\section{AUTHOR CONTRIBUTIONS}

Conceived and designed the manuscript: EK and CS. Wrote the manuscript: $\mathrm{AO}, \mathrm{PK}$, and JL have contributed equally to this work. Final revision: EK, CS, AO, PK, and JL.

\section{ACKNOWLEDGMENTS}

$\mathrm{AO}, \mathrm{PK}$, and JL are supported by Ph.D. fellowship from Fundação de Amparo à Pesquisa do Estado de São Paulo (FAPESP). CS is a research fellow of CNPq. This publication was made possible by Grants from FAPESP to CS; FAPESP Young Investigators Grants to EK; Conselho Nacional de Desenvolvimento Científico e Tecnológico ( $\mathrm{CNPq}$ ) to CS; and the Neuroscience Research Suport Centers (NAPNA). We thank George Anderson, CRC Scotland and London for English Editing.

of CD69 on PHA-and TPA-stimulated cells. Int J Immunopharmacol (1997) 19(3):143-8. doi:10.1016/S0192-0561(96)00070-7

11. Rodrigues-Mascarenhas S, Bloise FF, Moscat J, Rumjanek VM. Ouabain inhibits p38 activation in thymocytes. Cell Biol Int (2008) 32(10):1323-8. doi:10.1016/j.cellbi.2008.07.012

12. Matsumori A, Ono K, Nishio R, Igata H, Shioi T, Matsui S, et al. Modulation of cytokine production and protection against lethal endotoxemia by the cardiac glycoside ouabain. Circulation (1997) 96(5):1501-6. doi:10.1161/01. CIR.96.5.1501

13. Wen L, Huang Y, Xie X, Huang W, Yin J, Lin W, et al. Anti-inflammatory and antinociceptive activities of bufalin in rodents. Mediators Inflamm (2014) 2014:171839. doi:10.1155/2014/171839

14. Leite JA, Alves AK, Galvao JG, Teixeira MP, Cavalcante-Silva LH, Scavone $\mathrm{C}$, et al. Ouabain modulates zymosan-induced peritonitis in mice. Mediators Inflamm (2015) 2015:265798. doi:10.1155/2015/265798

15. Retamales-Ortega RVC, Inestrosa NC. P2C-type ATPases and their regulation. Mol Neurobiol (2015). doi:10.1007/s12035-014-9076-Z

16. Feraille E, Doucet A. Sodium-potassium-adenosinetriphosphatasedependent sodium transport in the kidney: hormonal control. Physiol Rev (2001) 81(1):345-418.

17. Bhavsar SK, Hosseinzadeh Z, Brenner D, Honisch S, Jilani K, Liu G, et al. Energy-sensitive regulation of $\mathrm{Na}+/ \mathrm{K}+$-ATPase by Janus kinase 2 . Am J Physiol Cell Physiol (2014) 306(4):C374-84. doi:10.1152/ajpcell.00320.2013

18. Kanai R, Ogawa H, Vilsen B, Cornelius F, Toyoshima C. Crystal structure of a $\mathrm{Na}+$-bound $\mathrm{Na}+, \mathrm{K}+-$ ATPase preceding the E1P state. Nature (2013) 502(7470):201-6. doi:10.1038/nature12578

19. Katz A, Lifshitz Y, Bab-Dinitz E, Kapri-Pardes E, Goldshleger R, Tal DM, et al. Selectivity of digitalis glycosides for isoforms of human Na,K-ATPase. J Biol Chem (2010) 285(25):19582-92. doi:10.1074/jbc.M110.119248 
20. Glynn I. Annual review prize lecture. 'All hands to the sodium pump'J Physiol (1993) 462:1-30. doi:10.1113/jphysiol.1993.sp019540

21. Garty H, Karlish SJ. Role of FXYD proteins in ion transport. Annu Rev Physiol (2006) 68:431-59. doi:10.1146/annurev.physiol.68.040104.131852

22. Lingrel JB. The physiological significance of the cardiotonic steroid/ ouabain-binding site of the Na,K-ATPase. Annu Rev Physiol (2010) 72:395-412. doi:10.1146/annurev-physiol-021909-135725

23. Reinhard L, Tidow $\mathrm{H}$, Clausen MJ, Nissen P. $\mathrm{Na}(+), \mathrm{K}(+)$-ATPase as a docking station: protein-protein complexes of the $\mathrm{Na}(+), \mathrm{K}(+)$-ATPase. Cell Mol Life Sci (2013) 70(2):205-22. doi:10.1007/s00018-012-1039-9

24. Geering $\mathrm{K}$. The functional role of beta subunits in oligomeric P-type ATPases. J Bioenerg Biomembr (2001) 33(5):425-38. doi:10.1023/A:1010623724749

25. Palmgren MG, Nissen P. P-type ATPases. Annu Rev Biophys (2011) 40:243-66. doi:10.1146/annurev.biophys.093008.131331

26. Lutsenko S, Kaplan JH. An essential role for the extracellular domain of the Na,K-ATPase beta-subunit in cation occlusion. Biochemistry (1993) 32(26):6737-43. doi:10.1021/bi00077a029

27. Peng L, Martin-Vasallo P, Sweadner KJ. Isoforms of Na,K-ATPase alpha and beta subunits in the rat cerebellum and in granule cell cultures. J Neurosci (1997) 17(10):3488-502.

28. Segel GB, Lichtman MA. Potassium transport in human blood lymphocytes treated with phytohemagglutinin. JClin Invest (1976) 58(6):1358-69. doi:10.1172/JCI108591

29. Prasad KV, Severini A, Kaplan JG. Sodium ion influx in proliferating lymphocytes: an early component of the mitogenic signal. Arch Biochem Biophys (1987) 252(2):515-25. doi:10.1016/0003-9861(87)90059-2

30. Marakhova II, Vereninov AA, Toropova FV, Vinogradova TA. Na, K-ATPase pump in activated human lymphocytes: on the mechanisms of rapid and long-term increase in $\mathrm{K}$ influxes during the initiation of phytohemagglutinin-induced proliferation. Biochim Biophys Acta (1998) 1368(1):61-72. doi:10.1016/S0005-2736(97)00164-8

31. Marakhova II, Vinogradova TA, Toropova FV. Na/K-pump and the cell response to mitogenic signal: regulatory mechanisms and relation to the blast transformation of human blood lymphocytes. Membr Cell Biol (2000) 14(2):253-61.

32. Vereninov AA, Marakhova II, Osipov VV, Toropova FV. Expression of mRNAs encoding the alpha 1 and the beta 1 subunits of $\mathrm{Na}+, \mathrm{K}(+)$-ATPase in human lymphocytes activated with phytohaemagglutinine. FEBS Lett (1993) 316(1):37-40. doi:10.1016/0014-5793(93)81732-F

33. Chiampanichayakul S, Szekeres A, Khunkaewla P, Moonsom S, Leksa V, Drbal K, et al. Engagement of Na,K-ATPase beta3 subunit by a specific $\mathrm{mAb}$ suppresses $\mathrm{T}$ and $\mathrm{B}$ lymphocyte activation. Int Immunol (2002) 14(12):1407-14. doi:10.1093/intimm/dxf112

34. Paul D, Soignier RD, Minor L, Tau H, Songu-Mize E, Gould HJ III. Regulation and pharmacological blockade of sodium-potassium ATPase: a novel pathway to neuropathy. J Neurol Sci (2014) 340(1-2):139-43. doi:10.1016/j. jns.2014.03.012

35. Wang F, Cai B, Li KC, Hu XY, Lu YJ, Wang Q, et al. FXYD2, a gamma subunit of $\mathrm{Na}(+), \mathrm{K}(+)$-ATPase, maintains persistent mechanical allodynia induced by inflammation. Cell Res (2015) 25(3):318-34. doi:10.1038/cr.2015.12

36. Vasconcelos AR, Kinoshita PF, Yshii LM, Marques Orellana AM, Bohmer $\mathrm{AE}$, de Sa Lima L, et al. Effects of intermittent fasting on age-related changes on $\mathrm{Na}, \mathrm{K}$-ATPase activity and oxidative status induced by lipopolysaccharide in rat hippocampus. Neurobiol Aging (2015) 36(5):1914-23. doi:10.1016/j. neurobiolaging.2015.02.020

37. Block L, Bjorklund U, Westerlund A, Jorneberg P, Biber B, Hansson E. A new concept affecting restoration of inflammation-reactive astrocytes. Neuroscience (2013) 250:536-45. doi:10.1016/j.neuroscience.2013.07.033

38. Scavone C, Munhoz CD, Kawamoto EM, Glezer I, de Sa Lima L, Marcourakis T, et al. Age-related changes in cyclic GMP and PKG-stimulated cerebellar Na,K-ATPase activity. Neurobiol Aging (2005) 26(6):907-16. doi:10.1016/j. neurobiolaging.2004.08.013

39. Oselkin M, Tian D, Bergold PJ. Low-dose cardiotonic steroids increase sodium-potassium ATPase activity that protects hippocampal slice cultures from experimental ischemia. Neurosci Lett (2010) 473(2):67-71. doi:10.1016/j. neulet.2009.10.021

40. Doty KR, Guillot-Sestier MV, Town T. The role of the immune system in neurodegenerative disorders: adaptive or maladaptive? Brain Res (2015) 1617:155-73. doi:10.1016/j.brainres.2014.09.008
41. Hawkes CA, McLaurin J. Selective targeting of perivascular macrophages for clearance of beta-amyloid in cerebral amyloid angiopathy. Proc Natl Acad Sci U S A (2009) 106(4):1261-6. doi:10.1073/pnas.0805453106

42. Lampron A, Pimentel-Coelho PM, Rivest S. Migration of bone marrow-derived cells into the central nervous system in models of neurodegeneration. J Comp Neurol (2013) 521(17):3863-76. doi:10.1002/cne.23363

43. Michaud JP, Bellavance MA, Prefontaine P, Rivest S. Real-time in vivo imaging reveals the ability of monocytes to clear vascular amyloid beta. Cell Rep (2013) 5(3):646-53. doi:10.1016/j.celrep.2013.10.010

44. Colangelo AM, Alberghina L, Papa M. Astrogliosis as a therapeutic target for neurodegenerative diseases. Neurosci Lett (2014) 565:59-64. doi:10.1016/j. neulet.2014.01.014

45. Hanisch UK, Kettenmann H. Microglia: active sensor and versatile effector cells in the normal and pathologic brain. Nat Neurosci (2007) 10(11):1387-94. doi:10.1038/nn1997

46. Yin $\mathrm{Z}, \mathrm{Yu} \mathrm{H}, \mathrm{Chen} \mathrm{S}, \mathrm{Ma} \mathrm{C}, \mathrm{Ma} \mathrm{X}, \mathrm{Xu} \mathrm{L}$, et al. Asiaticoside attenuates diabetes-induced cognition deficits by regulating PI3K/Akt/NF-kappaB pathway. Behav Brain Res (2015) 292:288-99. doi:10.1016/j.bbr.2015.06.024

47. Murrell JR, Randall JD, Rosoff J, Zhao JL, Jensen RV, Gullans SR, et al. Endogenous ouabain: upregulation of steroidogenic genes in hypertensive hypothalamus but not adrenal. Circulation (2005) 112(9):1301-8. doi:10.1161/CIRCULATIONAHA.105.554071

48. Jeremias IC, Scaini G, Constantino L, Vuolo F, Ferreira AK, Scherer EB, et al. The decrease on $\mathrm{Na}(+), \mathrm{K}(+)$-ATPase activity in the cortex, but not in hippocampus, is reverted by antioxidants in an animal model of sepsis. Mol Neurobiol (2012) 46(2):467-74. doi:10.1007/s12035-012-8297-2

49. Rosi S, Ramirez-Amaya V, Hauss-Wegrzyniak B, Wenk GL. Chronic brain inflammation leads to a decline in hippocampal NMDA-R1 receptors. J Neuroinflammation (2004) 1(1):12. doi:10.1186/1742-2094-1-12

50. Kairane C, Mahlapuu R, Ehrlich K, Zilmer M, Soomets U. The effects of different antioxidants on the activity of cerebrocortical MnSOD and Na,KATPase from post mortem Alzheimer's disease and age-matched normal brains. Curr Alzheimer Res (2014) 11(1):79-85. doi:10.2174/156720501131 06660179

51. Mark RJ, Hensley K, Butterfield DA, Mattson MP. Amyloid beta-peptide impairs ion-motive ATPase activities: evidence for a role in loss of neuronal Ca2+ homeostasis and cell death. J Neurosci (1995) 15(9):6239-49.

52. Ohnishi T, Yanazawa M, Sasahara T, Kitamura Y, Hiroaki H, Fukazawa Y, et al. Na, K-ATPase alpha3 is a death target of Alzheimer patient amyloid-beta assembly. Proc Natl Acad Sci U S A (2015) 112(32):E4465-74. doi:10.1073/ pnas. 1421182112

53. Vitvitsky VMGS, Keep RF, Albin RL, Banerjee R. Na+ and K+ ion imbalances in Alzheimer's disease. Biochim Biophys Acta (2012) 1822(11):1671-81. doi:10.1016/j.bbadis.2012.07.004

54. Lundborg C, Westerlund A, Bjorklund U, Biber B, Hansson E. Ifenprodil restores GDNF-evoked $\mathrm{Ca}(2+)$ signalling and $\mathrm{Na}(+) / \mathrm{K}(+)$-ATPase expression in inflammation-pretreated astrocytes. J Neurochem (2011) 119(4):686-96. doi:10.1111/j.1471-4159.2011.07465.x

55. Matos M, Augusto E, Agostinho P, Cunha RA, Chen JF. Antagonistic interaction between adenosine $\mathrm{A} 2 \mathrm{~A}$ receptors and $\mathrm{Na}+/ \mathrm{K}+$-ATPase-alpha2 controlling glutamate uptake in astrocytes. J Neurosci (2013) 33(47):18492-502. doi:10.1523/JNEUROSCI.1828-13.2013

56. Luan Z, Reddig K, Li HS. Loss of $\mathrm{Na}(+) / \mathrm{K}(+)$-ATPase in Drosophila photoreceptors leads to blindness and age-dependent neurodegeneration. Exp Neurol (2014) 261:791-801. doi:10.1016/j.expneurol.2014.08.025

57. Shrivastava AN, Redeker V, Fritz N, Pieri L, Almeida LG, Spolidoro M, et al. alpha-Synuclein assemblies sequester neuronal alpha3-Na+/K+-ATPase and impair $\mathrm{Na}+$ gradient. EMBO J (2015) 34(19):2408-23. doi:10.15252/ embj.201591397

58. Kaphzan H, Buffington SA, Ramaraj AB, Lingrel JB, Rasband MN, Santini E, et al. Genetic reduction of the alphal subunit of Na/K-ATPase corrects multiple hippocampal phenotypes in Angelman syndrome. Cell Rep (2013) 4(3):405-12. doi:10.1016/j.celrep.2013.07.005

59. Luan ZRK, Li HS. Loss of $\mathrm{Na}(+) / \mathrm{K}(+)$-ATPase in Drosophila photoreceptors leads to blindness and age-dependent neurodegeneration. Exp Neurol (2014) 261:791-801. doi:10.1016/j.expneurol.2014.08.025

60. Withering W. An Account of the Foxglove and Some of Its Medical Uses: With Practical Remarks on Dropsy and Other Diseases. London: GGJ and J Robinson (1785). 
61. Kometiani P, Li J, Gnudi L, Kahn BB, Askari A, Xie Z. Multiple signal transduction pathways link $\mathrm{Na}+\mathrm{K}+$-ATPase to growth-related genes in cardiac myocytes. The roles of Ras and mitogen-activated protein kinases. J Biol Chem (1998) 273(24):15249-56. doi:10.1074/jbc.273.24.15249

62. Nesher M, Shpolansky U, Rosen H, Lichtstein D. The digitalis-like steroid hormones: new mechanisms of action and biological significance. Life Sci (2007) 80(23):2093-107. doi:10.1016/j.lfs.2007.03.013

63. Aizman O, Aperia A. Na,K-ATPase as a signal transducer. Ann N Y Acad Sci (2003) 986:489-96. doi:10.1111/j.1749-6632.2003.tb07233.x

64. Nesher M, Dvela M, Igbokwe VU, Rosen H, Lichtstein D. Physiological roles of endogenous ouabain in normal rats. Am J Physiol Heart Circ Physiol (2009) 297(6):H2026-34. doi:10.1152/ajpheart.00734.2009

65. Toyoshima C, Kanai R, Cornelius F. First crystal structures of Na+,K+ATPase: new light on the oldest ion pump. Structure (2011) 19(12):1732-8. doi:10.1016/j.str.2011.10.016

66. Laursen M, Gregersen JL, Yatime L, Nissen P, Fedosova NU. Structures and characterization of digoxin- and bufalin-bound $\mathrm{Na}+\mathrm{K}+-\mathrm{ATPase}$ compared with the ouabain-bound complex. Proc Natl Acad Sci U S A (2015) 112(6):1755-60. doi:10.1073/pnas.1422997112

67. Goto A, Ishiguro T, Yamada K, Ishii M, Yoshioka M, Eguchi C, et al. Isolation of a urinary digitalis-like factor indistinguishable from digoxin. Biochem Biophys Res Commun (1990) 173(3):1093-101. doi:10.1016/ S0006-291X(05)80898-8

68. Hamlyn JM, Blaustein MP, Bova S, DuCharme DW, Harris DW, Mandel F, et al. Identification and characterization of a ouabain-like compound from human plasma. Proc Natl Acad Sci U S A (1991) 88(14):6259-63. doi:10.1073/ pnas.88.21.9907-d

69. Lichtstein D, Gati I, Samuelov S, Berson D, Rozenman Y, Landau L, et al. Identification of digitalis-like compounds in human cataractous lenses. Eur J Biochem (1993) 216(1):261-8. doi:10.1111/j.1432-1033.1993.tb18141.x

70. Bagrov AY, Fedorova OV, Dmitrieva RI, Howald WN, Hunter AP, Kuznetsova EA, et al. Characterization of a urinary bufodienolide Na+,K+-ATPase inhibitor in patients after acute myocardial infarction. Hypertension (1998) 31(5):1097-103. doi:10.1161/01.HYP.31.5.1097

71. Komiyama Y, Dong XH, Nishimura N, Masaki H, Yoshika M, Masuda $\mathrm{M}$, et al. A novel endogenous digitalis, telocinobufagin, exhibits elevated plasma levels in patients with terminal renal failure. Clin Biochem (2005) 38(1):36-45. doi:10.1016/j.clinbiochem.2004.08.005

72. Schoner W, Scheiner-Bobis G. Endogenous and exogenous cardiac glycosides: their roles in hypertension, salt metabolism, and cell growth. Am J Physiol Cell Physiol (2007) 293(2):C509-36. doi:10.1152/ajpcell.00098.2007

73. Lewis LK, Yandle TG, Hilton PJ, Jensen BP, Begg EJ, Nicholls MG. Endogenous ouabain is not ouabain. Hypertension (2014) 64(4):680-3. doi:10.1161/ HYPERTENSIONAHA.114.03919

74. de Vasconcelos DI, Leite JA, Carneiro LT, Piuvezam MR, de Lima MR, de Morais LC, et al. Anti-inflammatory and antinociceptive activity of ouabain in mice. Mediators Inflamm (2011) 2011:912925. doi:10.1155/2011/912925

75. Rong X, Ni W, Liu Y, Wen J, Qian C, Sun L, et al. Bufalin, a bioactive component of the Chinese medicine chansu, inhibits inflammation and invasion of human rheumatoid arthritis fibroblast-like synoviocytes. Inflammation (2014) 37(4):1050-8. doi:10.1007/s10753-014-9828-y

76. Jacob PL, Leite JA, Alves AK, Rodrigues YK, Amorim FM, Neris PL, et al. Immunomodulatory activity of ouabain in Leishmania (Leishmania) amazonensis-infected Swiss mice. Parasitol Res (2013) 112(3):1313-21. doi:10.1007/s00436-012-3146-9

77. Yang Q, Huang W, Jozwik C, Lin Y, Glasman M, Caohuy H, et al. Cardiac glycosides inhibit TNF-alpha/NF-kappaB signaling by blocking recruitment of TNF receptor-associated death domain to the TNF receptor. Proc Natl Acad Sci U S A (2005) 102(27):9631-6. doi:10.1073/pnas.0504097102

78. Manna SK, Sreenivasan Y, Sarkar A. Cardiac glycoside inhibits IL-8-induced biological responses by downregulating IL-8 receptors through altering membrane fluidity. JCell Physiol (2006) 207(1):195-207. doi:10.1002/ jcp. 20555

79. Fouser LA, Wright JF, Dunussi-Joannopoulos K, Collins M. Th17 cytokines and their emerging roles in inflammation and autoimmunity. Immunol Rev (2008) 226:87-102. doi:10.1111/j.1600-065X.2008.00712.x

80. Langrish CL, Chen Y, Blumenschein WM, Mattson J, Basham B, Sedgwick JD, et al. IL-23 drives a pathogenic T cell population that induces autoimmune inflammation. J Exp Med (2005) 201(2):233-40. doi:10.1084/jem.20041257
81. Annunziato F, Cosmi L, Santarlasci V, Maggi L, Liotta F, Mazzinghi B, et al. Phenotypic and functional features of human Th17 cells. J Exp Med (2007) 204(8):1849-61. doi:10.1084/jem.20070663

82. Ivanov II, McKenzie BS, Zhou L, Tadokoro CE, Lepelley A, Lafaille JJ, et al. The orphan nuclear receptor RORgammat directs the differentiation program of proinflammatory IL-17+ Thelper cells. Cell (2006) 126(6):1121-33. doi:10.1016/j.cell.2006.07.035

83. Huh JR, Leung MW, Huang P, Ryan DA, Krout MR, Malapaka RR, et al. Digoxin and its derivatives suppress TH17 cell differentiation by antagonizing RORgammat activity. Nature (2011) 472(7344):486-90. doi:10.1038/ nature09978

84. Wu J, Zhou C, Chen W, Xie A, Li J, Wang S, et al. Digoxin attenuates acute cardiac allograft rejection by antagonizing RORgammat activity. Transplantation (2013) 95(3):434-41. doi:10.1097/TP.0b013e31827a48f5

85. Fujita-Sato $\mathrm{S}$, Ito $\mathrm{S}$, Isobe $\mathrm{T}$, Ohyama $\mathrm{T}$, Wakabayashi $\mathrm{K}$, Morishita $\mathrm{K}$, et al. Structural basis of digoxin that antagonizes RORgamma $t$ receptor activity and suppresses Th17 cell differentiation and interleukin (IL)-17 production. J Biol Chem (2011) 286(36):31409-17. doi:10.1074/jbc.M111.254003

86. Akira S, Uematsu S, Takeuchi O. Pathogen recognition and innate immunity. Cell (2006) 124(4):783-801. doi:10.1016/j.cell.2006.02.015

87. Manunta P, Hamilton BP, Hamlyn JM. Structure-activity relationships for the hypertensinogenic activity of ouabain: role of the sugar and lactone ring. Hypertension (2001) 37(2 Pt 2):472-7. doi:10.1161/01.HYP.37.2.472

88. Abushik PA, Sibarov DA, Eaton MJ, Skatchkov SN, Antonov SM. Kainateinduced calcium overload of cortical neurons in vitro: dependence on expression of AMPAR GluA2-subunit and down-regulation by subnanomolar ouabain. Cell Calcium (2013) 54(2):95-104. doi:10.1016/j.ceca.2013.05.002

89. Li J, Khodus GR, Kruusmagi M, Kamali-Zare P, Liu XL, Eklof AC, et al. Ouabain protects against adverse developmental programming of the kidney. Nat Commun (2010) 1:42. doi:10.1038/ncomms1043

90. Kinoshita PF, Yshii LM, Vasconcelos AR, Orellana AM, Lima Lde S, Davel AP, et al. Signaling function of $\mathrm{Na}, \mathrm{K}-\mathrm{ATPase}$ induced by ouabain against LPS as an inflammation model in hippocampus. J Neuroinflammation (2014) 11(1):218. doi:10.1186/s12974-014-0218-z

91. Veldhuis WB, van der Stelt M, Delmas F, Gillet B, Veldink GA, Vliegenthart $\mathrm{JF}$, et al. In vivo excitotoxicity induced by ouabain, a $\mathrm{Na}+\mathrm{K}+$-ATPase inhibitor. J Cereb Blood Flow Metab (2003) 23(1):62-74. doi:10.1097/01. WCB.0000039287.37737.50

92. Kawamoto EM, Lima LS, Munhoz CD, Yshii LM, Kinoshita PF, Amara FG, et al. Influence of $\mathrm{N}$-methyl-D-aspartate receptors on ouabain activation of nuclear factor-kappaB in the rat hippocampus. J Neurosci Res (2012) 90(1):213-28. doi:10.1002/jnr.22745

93. Kaltschmidt B, Kaltschmidt C. NF-kappaB in the nervous system. Cold Spring Harb Perspect Biol (2009) 1(3):a001271. doi:10.1101/cshperspect.a001271

94. Forshammar J, Block L, Lundborg C, Biber B, Hansson E. Naloxone and ouabain in ultralow concentrations restore $\mathrm{Na}+\mathrm{K}+$-ATPase and cytoskeleton in lipopolysaccharide-treated astrocytes. J Biol Chem (2011) 286(36):31586-97. doi:10.1074/jbc.M111.247767

95. Forshammar J, Jorneberg P, Bjorklund U, Westerlund A, Lundborg C, Biber B, et al. Anti-inflammatory substances can influence some glial cell types but not others. Brain Res (2013) 1539:34-40. doi:10.1016/j. brainres.2013.09.052

96. Kaur S, Rehni AK, Singh N, Jaggi AS. Studies on cerebral protection of digoxin against ischemia/reperfusion injury in mice. Yakugaku Zasshi (2009) 129(4):435-43. doi:10.1248/yakushi.129.435

97. Wilinski B, Wilinski J, Somogyi E, Piotrowska J, Goralska M. Digoxin increases hydrogen sulfide concentrations in brain, heart and kidney tissues in mice. Pharmacol Rep (2011) 63(5):1243-7. doi:10.1016/S1734-1140(11)70645-4

98. Eto K, Asada T, Arima K, Makifuchi T, Kimura H. Brain hydrogen sulfide is severely decreased in Alzheimer's disease. Biochem Biophys Res Commun (2002) 293(5):1485-8. doi:10.1016/S0006-291X(02)00422-9

99. Dunn DE, He DN, Yang P, Johansen M, Newman RA, Lo DC. In vitro and in vivo neuroprotective activity of the cardiac glycoside oleandrin from Nerium oleander in brain slice-based stroke models. J Neurochem (2011) 119(4):805-14. doi:10.1111/j.1471-4159.2011.07439.x

100. Van Kanegan MJ, He DN, Dunn DE, Yang P, Newman RA, West AE, et al. BDNF mediates neuroprotection against oxygen-glucose deprivation by the cardiac glycoside oleandrin. J Neurosci (2014) 34(3):963-8. doi:10.1523/ JNEUROSCI.2700-13.2014 
101. Sun Y, Dong Z, Khodabakhsh H, Chatterjee S, Guo S. Zebrafish chemical screening reveals the impairment of dopaminergic neuronal survival by cardiac glycosides. PLoS One (2012) 7(4):e35645. doi:10.1371/journal. pone. 0035645

102. McCarty MF. Marinobufagenin and cyclic strain may activate endothelial NADPH oxidase, contributing to the adverse impact of salty diets on vascular and cerebral health. Med Hypotheses (2012) 78(2):191-6. doi:10.1016/j. mehy.2011.09.028

103. Rosenblat JD, Cha DS, Mansur RB, McIntyre RS. Inflamed moods: a review of the interactions between inflammation and mood disorders. Prog Neuropsychopharmacol Biol Psychiatry (2014) 53:23-34. doi:10.1016/j. pnpbp.2014.01.013

104. Looney SW, el-Mallakh RS. Meta-analysis of erythrocyte Na, K-ATPase activity in bipolar illness. Depress Anxiety (1997) 5(2):53-65. doi:10.1002/ (SICI) 1520-6394(1997)5:2<53::AID-DA1>3.0.CO;2-6

105. Elhaik E, Zandi P. Dysregulation of the NF-kappaB pathway as a potential inducer of bipolar disorder. J Psychiatr Res (2015) 70:18-27. doi:10.1016/j. jpsychires.2015.08.009

106. Goldstein I, Levy T, Galili D, Ovadia H, Yirmiya R, Rosen H, et al. Involvement of $\mathrm{Na}(+), \mathrm{K}(+)$-ATPase and endogenous digitalis-like compounds in depressive disorders. Biol Psychiatry (2006) 60(5):491-9. doi:10.1016/j. biopsych.2005.12.021

107. Dvela M, Rosen H, Feldmann T, Nesher M, Lichtstein D. Diverse biological responses to different cardiotonic steroids. Pathophysiology (2007) 14(3-4):159-66. doi:10.1016/j.pathophys.2007.09.011

108. Tonin PT, Valvassori SS, Lopes-Borges J, Mariot E, Varela RB, Teixeira $\mathrm{AL}$, et al. Effects of ouabain on cytokine/chemokine levels in an animal model of mania. J Neuroimmunol (2014) 276(1-2):236-9. doi:10.1016/j. jneuroim.2014.09.007

109. Jornada LK, Moretti M, Valvassori SS, Ferreira CL, Padilha PT, Arent $\mathrm{CO}$, et al. Effects of mood stabilizers on hippocampus and amygdala BDNF levels in an animal model of mania induced by ouabain. J Psychiatr Res (2010) 44(8):506-10. doi:10.1016/j. jpsychires.2009.11.002

110. Gao Y, Payne RS, Schurr A, Hougland T, Lord J, Herman L, et al. Memantine reduces mania-like symptoms in animal models. Psychiatry Res (2011) 188(3):366-71. doi:10.1016/j.psychres.2010.12.030

111. Serra G, Demontis F, Serra F, De Chiara L, Spoto A, Girardi P, et al. Memantine: new prospective in bipolar disorder treatment. World J Psychiatry (2014) 4(4):80-90. doi:10.5498/wjp.v4.i4.80
112. Zdanys K, Tampi RR. A systematic review of off-label uses of memantine for psychiatric disorders. Prog Neuropsychopharmacol Biol Psychiatry (2008) 32(6):1362-74. doi:10.1016/j.pnpbp.2008.01.008

113. El-Mallakh RS, Schurr A, Payne RS, Li R. Ouabain induction of cycling of multiple spike responses in hippocampal slices is delayed by lithium. J Psychiatr Res (2000) 34(2):115-20. doi:10.1016/S0022-3956(99)00045-X

114. Souza LC, Wilhelm EA, Bortolatto CF, Nogueira CW, Boeira SP, Jesse CR. The protective effect of melatonin against brain oxidative stress and hyperlocomotion in a rat model of mania induced by ouabain. Behav Brain Res (2014) 271:316-24. doi:10.1016/j.bbr.2014.06.030

115. Riegel RE, Valvassori SS, Elias G, Reus GZ, Steckert AV, de Souza B, et al. Animal model of mania induced by ouabain: evidence of oxidative stress in submitochondrial particles of the rat brain. Neurochem Int (2009) 55(7):491-5. doi:10.1016/j.neuint.2009.05.003

116. Hamid H, Gao Y, Lei Z, Hougland MT, El-Mallakh RS. Effect of ouabain on sodium pump alpha-isoform expression in an animal model of mania. Prog Neuropsychopharmacol Biol Psychiatry (2009) 33(7):1103-6. doi:10.1016/j. pnpbp.2009.06.002

117. Grider G, El-Mallakh RS, Huff MO, Buss TJ, Miller J, Valdes R Jr. Endogenous digoxin-like immunoreactive factor (DLIF) serum concentrations are decreased in manic bipolar patients compared to normal controls. J Affect Disord (1999) 54(3):261-7. doi:10.1016/S0165-0327(98)00208-0

118. El-Mallakh RS, Stoddard M, Jortani SA, El-Masri MA, Sephton S, Valdes R Jr. Aberrant regulation of endogenous ouabain-like factor in bipolar subjects. Psychiatry Res (2010) 178(1):116-20. doi:10.1016/j.psychres.2009.03.032

119. Modabbernia A, Taslimi S, Brietzke E, Ashrafi M. Cytokine alterations in bipolar disorder: a meta-analysis of 30 studies. Biol Psychiatry (2013) 74(1):15-25. doi:10.1016/j.biopsych.2013.01.007

Conflict of Interest Statement: The authors declare that the research was conducted in the absence of any commercial or financial relationships that could be construed as a potential conflict of interest.

Copyright (c) 2016 Orellana, Kinoshita, Leite, Kawamoto and Scavone. This is an open-access article distributed under the terms of the Creative Commons Attribution License (CC BY). The use, distribution or reproduction in other forums is permitted, provided the original author(s) or licensor are credited and that the original publication in this journal is cited, in accordance with accepted academic practice. No use, distribution or reproduction is permitted which does not comply with these terms. 